\title{
MOBILE PHONE ACCIDENTS - EXPERIENCE OF INDIA
}

\author{
H. Abdul Shabeer ${ }^{1}$, Wahida Banu ${ }^{2}$ \\ ${ }^{1}$ Anna University, Coimbatore \\ E-mail:abdulshabeer@gmail.com \\ ${ }^{2}$ Principal Government College of Engineering, Salem
}

Every year nearly 1.4 million people have been killed because of they are wireless customers and their over-bearing cell phones. While in India, an estimated 1.35 lakhs person died due to road accident in 2010 , which is approximately $10 \%$ of road accident fatalities worldwide and these figures are the highest in the world. But still no research has been carried out to find the number of drivers using cell phone involved in road accident and very limited efforts has been carried out to prevent accident due to cell phone usage. To our knowledge this is the first survey carried out in India to determine the number of drivers involved in an accident due to mobile phone use. With the aim of preventing such accidents, it is proposed to develop a highly efficient automatic system for early detection of incoming and outgoing call, by placing an antenna along with mobile detection unit above the driver seat. This unit is capable of distinguishing whether the cell phone used either by the driver or by the passenger, if the driver uses of cell phone is detected, a safety application named Cellphone Accident Preventer (C.A.P.) which is developed using J2ME will be automatically load on the driver's cell phone which helps in eliminating the risk of accidents from occurring, at the same time ensuring that the user does not miss any emergency call. The research has been extended to show how far the system will help in preventing accidents and to what extent this system will help in reducing the Indian economic loss incurred unnecessarily due to road accident fatalities.

Keyword: Mobile Phone Accident, location of vehicle using a mobile phone, cell phone detection, Mobile safety application, Risk of using a mobile phone, Mobile Jammer

\section{Introduction}

\subsection{Global System for Mobile Communication}

The general architecture of a GSM network is shown on Figure 1. The GSM system consists of several functional elements which include mobile switching centres (MSC), base stations (BSC) with associated base transceivers (BTS) and a gateway MSC. GSM mobile terminal or mobile stations are able to communicate across the air interface $\mathrm{U}_{\mathrm{M}}$, with a base BTS using a small cell in which the mobile unit is located. This communication a BTS takes place through radio channels. BSC is connected to the MSC through a dedicated line or a radio communication link. The BSC reserves radio frequencies, manages the handover of the mobile station from one cell to another within the BSS (base station subsystem). The MSC interface to the PSTN (public switched telephone network) is called as the gateway MSC. MSC incorporates functions including home location register (HLR), visitor location register (VLR), authentication register $(\mathrm{AuC})$ and equipment identity register (EIR). The HLR and VLR together with MSC provide the call routing and roaming capabilities of the GSM. The HLR stores information (both permanent and temporary) about each of the mobile station which belongs to it. The VLR register and maintains information about a mobile station that is currently physically in the region covered by MSC. VLR becomes important when the user leaves the area served by his home MSC. The two registers are used for authentication and security purposes. The EIR is a database that contains a list of all valid mobile equipment on the network, where each mobile station is identified by its international mobile equipment identity (IMEI).

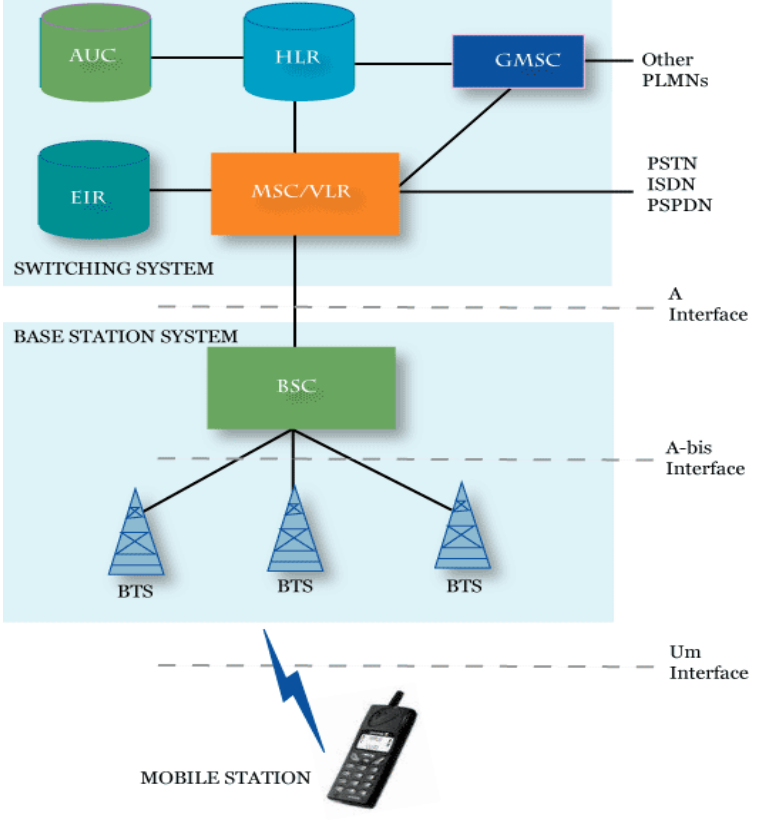

Figure 1. GSM Architecture 


\subsection{Distraction}

Talking or texting, using a cell phone while driving, is a major distraction leading to an accident. An immediate hazard for the driver is dialling a phone while a more serious issue is conversing on the phone. Such distractions are classified into two different categories namely,

1. Physical distraction: Which involves removing of one hand from the steering wheel to hold and operate the phone and visual distraction which involves taking one's eyes off the road to pick and put down the phone as well as dial numbers.

2. Cognitive distraction: Cognitive (mental) distraction occurred when tasks are performed concurrently, i.e., when a driver is using a hand-held or hands-free mobile phone while driving, she or he must divide their attention between operating and maintaining the conversation and operating the car while manoeuvring through traffic phone and maintaining the conversation and part to operating the vehicle and responding to the constantly changing road and traffic conditions.

\section{Motivation}

Driver distraction is one of the leading causes of motor vehicle accidents with driver distraction while using cell phone is the most common and challenging. An estimated 1.35 persons died in 2010, due to road crashes in India with an average of more than one death and four injuries every minute, accounted nearly $10 \%$ of global accident.

The report 'Road accidents in India' by the Transport Research Wing of the Ministry of Road transport and Highways, Government of India shows that "driver fault" is the single most important factor which accounted for $81 \%$ of total accidents. According to World Health Organization (WHO), road traffic crashes rank as the 9th leading cause of death and account for $2.2 \%$ of deaths globally. This number is expected to increase and rank as the 5th leading cause by 2030 if no action is taken to address the current crisis. Road traffic fatalities are forecast to rise from the current level of nearly 1.3 million deaths annually to more than 1.9 million deaths per year by 2020. According to National Safety Council (NSC) of U.S., it is estimated that at least $28 \%$ of all traffic crashes or at least 1.6 million crashes each year involves drivers using cell phones. The study by the Governors Highway Safety Association (GHSA), a nonprofit group that works to improve traffic safety, critically reviewed research of 350 scientific papers published since 2000 and concluded that driving distractions, primarily using cell phones and other electronic devices are associated with up to 25 percent of car crashes.

Having established this background it is important to draw attention to the idea that limited research work has been carried on to identify the percentage of cell phone distractions behind the crashes in India. This is of vital importance because the number of cell phone subscribers and motor vehicle is far greater than U.S.A. In order to make efforts to change this scenario there is a need to develop and implement strong mechanisms for prevention of mobile phone use while driving.

\section{Literature Review}

The concern of distracted driving can be tied to the research carried by Bruyas et al. (2008) which found attention sharing generated by phone use appears to increase the driver's mental workload thereby overloading the driver's cognitive capacities and impaired the driving performance. The study carried out on cognitive distraction by Harbluk et al. (2002), Strayer et al. (2003) shows, during the cell phone conversation, drivers are observed to be looking at the sky much more often, not at the road, traffic, or road signs. It is commonly observed that, while the drivers are in-depth conversation, they simply ignore the other road users and even close their eyes as they are imbibed in their talk. This is counterproductive to driving safely. The outcome of the research carried out by Crundall et al. (2005) show, driver behaviours such as impaired gap judgment, reduced sensitivity to road conditions, poor lane maintenance, and the increase in reaction time to driving-related events can all be as a result of distracted driving. The goal of driver identification task is to classify drivers from their driving behaviour characteristics, and distraction detection identifies whether the driver is under distraction due to secondary tasks.

The work carried by James (2011) show, driver distraction is an obvious risk and it is not difficult to understand, since everywhere anyone in traffic can look at the people who are constantly in a head-down driving position as they try to dial a number, changing music on smart phone; watch those drivers engaged in conversation who cannot maintain consistent speed, drift towards the centre line, or do not move when the light changes from red to green. Appropriately identifying driver distraction in real time is a critical challenge in developing these distraction mitigation systems, especially in detection of cognitive distraction which needs integration of a number 
of eye movement measures (e.g., blink frequency, fixation duration, and pursuit measurements) and performance measures (e.g., steering wheel movements and lane position) across a relatively long time interval but unfortunately this function was not well developed. The study carried by Liang (2009) show, differences in visual behaviour and driving performance associated with different types of distraction was found by using different sets of sensors and algorithms. The algorithms for distraction detection are mostly based either on eye measures or on driver performance measures (e.g., speed, lane position, and steering).

The technique proposed by Azman et al. (2010) is based on a physiological measurement to detect driver cognitive distraction. Two types of physiological measurements, eye and mouth movements are obtained using the faceLab seeing machine (it's a technology with a focus on vision based human machine interfaces which tracks human faces and certain facial features) and their relationship to each other are analysed using Pearson-r correlation. Their analysis proved that using a combination of eye and mouth movements as well as other existing features may greatly improve the performance of a driver cognitive distraction detection system. The work carried by Rongben et al. (2004) monitors the relationship between mouth movement and driver fatigue or distraction using a camera. Normally, the mouth is hardly open when the driver is alert. The maximum width and maximum height can indicate different levels of distraction. The height between top lip and the bottom lip varies greatly when one is talking, yawning or even thinking. In human science and psychological studies, it has been proved that mouth movement was a good indicator of a human's state of mind. This system will warn the driver once the distraction is detected.

There were few more techniques proposed by the researchers to detect the drivers distraction based on only eyes. For example, a technique proposed by Hayhoe (2004) for detecting driver's distraction by linking eye movements (fixation, saccade, and smooth pursuit), cognitive workload and distraction. Fixations occur when an observer's eyes are nearly stationary. Saccades are very fast movements that occur when visual attention shifts from one location to another (i.e., When drivers try to get their phone from the pocket or observing the display of the phone to find who is calling) while, smooth pursuits occur when an observer tracks a moving object such as a passing vehicle. Further, Liang et al. (2007) also uses the eye movement as their main feature to detect cognitive distraction on a driver. They used blinking, saccade, eyelid movement and pupil diameter and the characteristics of fixations, saccades and smooth pursuits to recognize the patterns of eye movements. The research proposed by Fisher et al. (2009) tracks the driver's eye using a sensor to determine whether the driver is distracted while using cell phone and a warning signs is given to the driver which effectively increase the driver attention to the roadway. Similarly, the work carried out by Miyaji et al. (2009) shows, the standard deviations of eye movement and head movement could be suitable for detecting the states of cognitive distraction (drivers divert their attention and focus on the topic of the phone conversation). All of these techniques introduced a forward warning system that employs driver behavioural information. These systems determine driver distraction when it detects that the driver was not looking straight ahead.

There are few more studies which consider the position of head along with eye gaze to detect distraction and some studies also considers vehicle surrounding state. For example, the research carried by Pohl et al. (2007) used head pose (driver will usually tilt the head towards left or right when they engage in conversation) and eye gaze information to model the visual distraction level, which was time dependent on the visual focus, with the assumption that the visual distraction level was nonlinear: Visual distraction increased with time (when the driver looked away from the road scene) but nearly instantaneously decreased (when the driver refocused on the road scene). Based on the pose/eye signals, they established their algorithm for visual distraction detection. First, they used a distraction calculation to compute the instantaneous distraction level. Then, a distraction decision maker determined whether the current distraction level represented a potentially distracted driver.

The techniques proposed by Doshi and Trivedi (2009) fused head orientation detection and a saliency map of the surroundings to determine whether there was a salient object in the driver's view, which gave an indication of whether a driver's head turn was motivated by the goal in his/her mind or some distracting object/event in the environment. The non-contact driver monitoring systems proposed by Takemura et al. (2003) analyse the facial expressions through video, as well as vehicle dynamics through on-board navigation sensors and develop a warning signals was sent to the driver prior to a potential crash.

The approach carried out by Pohl et al. (2007) makes use of the driver's face vector which in principle was the detection of direction of the driver's nose tip, and eyeball detection to prevent the distraction. The processes start if the vehicle departs from the lane and the driver was detected as distracted, then an intervention was triggered which sends a warning to the driver. The study carried by Itoh (2009) pointed out, that performing a cognitively distracting secondary task (e.g., talking or thinking about something) during driving would decrease the driver's temperature at the tip of the nose, and this effect was reproducible. Similarly, it was reported by Wesley et al. (2010) that a considerable and consistent skin temperature changes was measured by using physiological sensor that could be observed during cognitive and visual distractions. 
The research demonstrated by Dong et al. (2010) show, a real-time tracking kernel for stereo cameras to estimate face pose and face animation, including the movement of the eyelid, eyeball, eyebrow, and mouth, for driver inattention detection. The technique proposed by Smith et al. (2003) was to analysis global motion and colour statistics to robustly track a driver's facial features. Using these features, they estimated continuous gaze direction. Once distraction was detected, a beep or warning message was given to the driver. However, these methods cannot always localize facial features when the driver wears eyeglasses, makes conversation, closes his eyes, or rotates his head. It also failed to work at night.

Many researchers consider the fact that even small improvements in safety may have an impact on reducing deaths in vehicle crashes and carried out a various work to determine whether the use of a speech recognition system, could control in-vehicle systems and suggested as a solution to driver distraction. The speech recognition system proposed by Itoh et al. (2004) allows drivers to utter a command that is recognized by the interface to control equipments in question such as turn on a radio or to enter data such as a destination. It measures the driving performance by using speech recognition system when compare to manual and found a significant decrease in the standard deviation of lateral lane position. The study carried out by Forlines et al. (2005) on a simulated driving task, by comparing speech with a manual system and found speech recognition system was more efficient and less distracting.

The studies proposed by Itoh et al. (2004), Forlines et al. (2005) have shown that drivers can achieve better and safer driving performance while using speech interactive systems to operate an in-vehicle system compared to manual interfaces. Although providing better interfaces, operating a speech interactive system will still divert a driver's attention away from his or her primary driving task with varying degrees of distraction. Ideally, drivers should pay primary attention to driving, rather than any secondary tasks. It was later found out by Jannette and Mark (2009) that, both manual and speech control in secondary IVIS interaction tasks led to significant increases in reaction times and found no consistent significant difference in number of steering reversals i.e., in deviation of lane position. Similarly, result obtained by Lee et al. (2001) shows, speech controlled in-car systems leads to an increase in reaction times. The technique proposed by Gellatly and Dingus (1998) measures the task performance of a speech recognition system and found task completion time will decrease mostly between manual conditions. In some case, the results of task performance are a bit more mixed. For example, drivers can often dial a phone number more rapidly while driving using thumb dialling of a hand-held unit than speaking the phone number.

Few more limitation of speech recognition system raises the issue, for example, a study carried by Lawrence et al. (2005) found, a car is particularly difficult environment for speech recognition due to environmental noise and competing vehicle sound sources. The work carried by Hansen (Hansen 1996) show, a sophisticated speech system should also be able to distinguish between speech directed to it and other auditory input. More importantly, the drivers also had to modify their vocal effort to overcome noise levels in their cars. Such effects on speech production (e.g., speech under stress) can degrade the performance of automatic speech recognition (ASR) system more than the ambient noise itself. The work carried by Brouwer et al. (1991) show, the speech recognition technologies will aid older drivers in their performance of concurrent tasks while driving. The study carried out by comparing two email systems - simple speech vs. non speech is proposed by John et al. (2001). This research found, speech-based interaction introduced a significant cognitive load. More guidelines should be focused on speed recognition system since as real human speech, especially for cognitively-loaded humans, is highly diffluent, full of re-starts and revisions, "uhms" and "ahs", fragmented ungrammatical sentences, etc.

The study based on drivers observed behaviour when performing in-vehicle common tasks such as operating a cell phone was analysed by Jinesh (Jinesh, 2011). The study employs the UTDrive platform a car equipped with multiple sensors, including cameras, microphones, and Controller Area Network-Bus (CAN-Bus) information. The purpose of the analysis was to identify relevant features extracted from a frontal video camera and the car CAN-Bus data that may used to distinguish between normal and task driving conditions. Once distraction was identified, a warning or alert was given to the driver.

The study carried by Kircher et al. (2009) developed a system which detect and prevents the driver distraction. Authors designed a vehicle which was instrumented with video cameras, an automatic eye tracker and GPS receivers. Further, data were read from the CAN bus of the car. The data were logged continuously with high frequency. The log system operated autonomously. During the first ten days a behavioural baseline was collected. Afterwards the warnings were activated, such that the drivers received distraction warnings in form of a vibration in the seat when the algorithm determined that they had looked away from the forward roadway too much.

The work carried by Choi et al. (2007) uses UTDrive corpus which is a subset of driving data. The UTDrive corpus consists of rich multimodal driving data synchronously acquired in actual driving 
environment. The recording data are two video streams (driver face and front view of vehicle), audio streams from a five-channel microphone array and a close-talk microphone array, brake and gas pedal pressure sensors, following distance, CAN(Controlled Area Network)-Bus information (steering wheel angle, vehicle speed, engine speed, and brake position), and GPS information. The data analysis of longterm behaviour and distracted driving was compared to the non-distracted (neutral). Gaussian Mixture Model (GMM) and Hidden Markov Models (HMM) frameworks were used to focus on driver behaviour modelling and to capture the sequence of driving characteristics acquired from the vehicle's CAN-Bus information to detect distraction. Further, their results showed that the average vehicle speed was lower under a distracted driving, when compared to neutral driving. Also distracted driving had a wider neutralized short-term variance than non-distracted (neutral) driving. Once these types of variation were observed, it will indicate the driver through warning message.

Many researchers make use of advanced techniques to prevent distraction. For example, the approach carried by Zhang et al. (2004) uses a data mining techniques to successfully detect cognitive distraction using various measures. While, the study performed by Liang et al. (2007, 2007a), uses decision tree technique to estimate driver cognitive workload from eye glances, and driving performance measures using Support Vector Machines (SVMs) and Bayesian Networks (BNs) to successfully identified the presence of cognitive distraction from eye movements and driving performance but, glances were sensitive to task complexity and visual demand (Green, 1999). Similarly, Chad et al. (2005) developed an Advanced Driver Assistance (ADA) to prevent driver from getting distraction due to the cell phone using Bayesian Networks. They used sensors/actuators to collect context information of both driver and vehicle.

The technique developed by Yulan et al. (2007) used support vector machines (SVMs), a data mining method, to develop a real-time approach for detecting cognitive distraction using driver's eye movements and driving performance data. This approach assessed the discrete state of cognitive distraction, but did not predict the continuous level of distraction. Once distraction was detected, they use ADA system to interact with the driver. A cloud computing based decision support system (DSS) proposed by Shah and Rakib (2011) to prevent the drivers from using in-vehicle hand-held devices while driving. As a first step, it determine whether the vehicle was in motion using odometer reading or using an onboard GPS navigation system and it captures video and audio data inside the vehicle using in-vehicle camera for the detection of driver's carrying or interfacing with hand-held device. Once it detected, a warning message was given to driver.

The study examined by Cameron and Keith (2011) makes use of computer vision in Advanced Driver Assistance Systems, specifically for determining the level of distraction that the driver is suffering from. ADAS utilizes computer vision as well as lane detection in order to obtain physical information about the driver and the accuracy of their driving. First, the computer tracks the face of the driver using an AdaBoost algorithm and light compensation methods. The driver assist system then collects data through methods of measurement such as percentage of eyelid closure (PERCLOS), gaze direction, and yawn frequency, for later computations. The computer condenses the gathered information into a single quantitative variable using fuzzy integration. Based upon the data the system is able to analyse, it can identify when driving errors transpire or when they are more likely to occur. After producing the driver index the computer decides whether to alert the driver if they are overly fatigued, or step in to compensate for unintended activity.

There were few studies carried out by the researcher to prevent distracted driving due to cell phone by providing traffic or driver state to the caller. For example the study carried by Mike and Sara (2005) explores the possibility of reducing distraction by providing callers with remote information about the driver's traffic. Similarly, the work carried by Huang and Trivedi (2003) towards the development of novel driver assistance system, "Visual Capture, Analysis and Televiewing (VCAT)" which provide an example of a context-aware system, as one that attempts to alleviate driver distraction caused when using a mobile phone, by providing contextual information to the remote caller. This enables the remote party to observe the driving context while the conversation is taking place, as though they were a passenger in the car. This technology is envisaged to give the electronic "passenger" the same access to visual cues, allowing them the ability to alter the conversation style, as though they were witnessing the same thing as a passenger.

CarCoach, an educational car system proposed by Sharon et al. (2005) was based on generalized layered architecture. It used different sensors and inducers like temperature, humidity, pressure, stress, car gear state, GPS and many more attached inside the vehicle. Based on the sensors, stress was measured on a driving activity such as driving in reveres or performing manoeuvres such as changing lanes, turning etc. Application was meant to suppress the cellular phone rings as long as when the driver under stress was detected. The stress was measured based on the behaviour of drivers, which might be potentially detected by using pressure sensors on the steering wheel, with the assumption that the amount of pressure applied on the steering wheel often increased when the driver was in stress. 
The study carried by Healey (2005) collects and analyses physiological data such as electrocardiogram (ECG), electromyogram (EMG), skin conductance and respiration during real world driving tasks to determine a driver's relative stress level. During high stress situations incoming cell phone calls was diverted to voice mail and navigation systems were programmed to present the driver with only the most critical information. The study based on electroencephalography (EEG) signal which contain information about the task engagement level and mental workload was proposed by Berka et al. (2007). Once a cognitive or visual distraction found, an alert was activated to the driver. While, the outcome of the research carried by (Bouchner, 2006) shows, EEG was extremely dynamic and sensitive to outside factors. In addition, EEG patterns vary between individuals.

The research carried by Amardeep et al. (2008) proposed an initial analysis of a system for detecting driver distraction using data from the Controller Area Network (CAN) and motion sensor (accelerometer and gyroscope). This research mainly focuses on distractions perceivable with leg and head movements of the driver. A sensor on the leg will indicate transitions between the accelerator and brake. A sensor on the head will indicate the movement of the head from left to right or a tilt to answer a phone call. The leg and the head movements are measured using a tri-axial accelerometer and bi-axial gyroscope mounted on the sensor node. Once variation in speed and movement of the head is detected a warning or corrective mechanisms was used to reduce the intensity of accidents which may cause due to driver distractions.

The work carried by Chieh-Chih et al. (2012) proposed a system which located the cars on the road on which drivers were distracted, and it provided a warning message to the driver along with it also displayed message (e.g., Distracted !) to the surrounding cars through IVI system that would be visualized on top of their associated vehicles. They implemented system using FaceAPI and an RGB-D camera that could track face and hand postures. The system models and tracks the users face and determines whether or not the driver is looked forward. They model this attentive gaze with a rectangular boundary. When the driver's gaze was within the rectangle, no warning was produced, but when the driver was not looking at the road, the gaze would be shown outside of the rectangular region, and the Distracted warning was produced. A system proposed by Marie (2010) on detecting motion of a cell phone and disabling the use of the cell phone while moving or driving. The system included: a cell phone, a sensor to detect motion of the cell phone, software in the cell phone to disable the use of the cell phone when motion was detected.

There are many active efforts taken by the researcher to prevent the driver from getting distracted due to in-vehicle technology like cell phone, however, very limited research is identified wherein methods to differentiate whether the cell phone used in vehicle is either a driver or the passenger. For example, the study carried by Hon et al. (2011) presents a phone based sensing system, referred to as driver detection system (DDS), to determine if a user in a moving vehicle is a driver or a passenger by using various user micro-movements that can be detected using the mobile phone sensors (accelerometer, gyroscope, compass and microphone) which are capable of capturing and inferring significant amounts of information about the user's status and activities. This detection is based on inferring which part of the vehicle the user is present in, such as passenger side vs. driver side or front vs. rear, the directions in which the driver and a right side passenger reach for a seatbelt and wears it are different, as well as some key activities performed by the driver. Further, the system helps the mobile device's to identify the user's available attention and focus, enabling it to control delivery of potentially interrupting events such as incoming calls and messages.

The research carried by Jie et al. (2011) developed a cell phone detection scheme using an acoustic approach wherein a phone leverages the built-in Bluetooth and a car stereo to generate a series of high frequency beeps over the stereo. The phone records these beeps, which are spaced in time across the left, right, and if available, front and rear speakers, and times their arrival. Using a differential range approach to estimate the phone's distance from the car's centre, a passenger or driver classification is made. Further, Shabeer and Wahida Banu (2009) proposed a system which measures speed of the vehicle using digital speedometer and transmits the speed to the application installed in the driver's cell phone and change the profile of the cell phone from loud to silent once the speed exceeds a predefined speed.

Apart from these efforts, there have been some contributions which help in reducing the level of driver distraction while using their cell phone by allowing methods to promote ease of handling and interaction. The technique proposed by Janne and Jason (2011) reduces the need to operate a mobile phone while driving by using context-awareness such as by notifying the location and movement of the call recipient to the caller. While, Kevin et al. (2008) present BlindSight, which is a prototype application having the ability to replace the traditionally visual in-call menu of a mobile phone. Users interact using the phone keypad, without looking at the screen i.e., users with access to personal information stored on their mobile phone while talking on the phone. BlindSight responds with auditory feedback. This feedback is heard only by the user, not by the person on the other end of the line. 


\section{Case Study}

The major objective of this study was to investigate the percentage of drivers who met with an accident due to usage of mobile phone while behind the wheel in India. Although extensive research has been carried out regarding this in countries like U.S., no single study exists which adequately covers a percentage of accidents involving mobile phone in India.

\subsection{Participate and Procedure}

To study the risk associated with the usage of mobile phone while driving, a set of questions was asked to the drivers by interview or through an online survey containing the same set of questions. From the total sample of 650 targeted we received complete response from 579 participants. In addition to certain questions not considered in this report, participants were asked the following important queries,

1. Have you used your Mobile phone while driving (Yes/No)?

2. Do you personally think using a mobile phone while driving would significantly increase the chance of an accident (Yes/No)?

3. Have you met with an accident by using a mobile phone while driving (Yes/No)?

4. What extent do you think the use of mobile phone while driving should be restricted for safety reasons?

a) Total ban

b) No Restrictions

c) Technology should be developed in such a way that drivers can attend emergency call only when he parks the vehicle in a safe place.

\subsection{Results}

The majority of the drivers 475 (82\%) agreed use of mobile phone while driving. 527 drivers (91.1\%) identified that using a mobile phone while driving will increases the chances of meeting with an accident. $180(31 \%)$ of drivers admitted that they have met with an accident as a result of using a cell phone. 428 drivers (74\%) indicated that advanced technology should be developed to restrict the driver from using a mobile phone while providing provision to make or a receive call when the vehicle is stopped. 150 respondents $(26 \%)$ opted for a total ban on the use of mobile phone while driving. Nearly 400 drivers (69\%) admitted that they will drive fast if mobile communication was completely blocked inside the vehicle by using technologies like mobile jammers. The summary of complete result is shown on Figure 2.

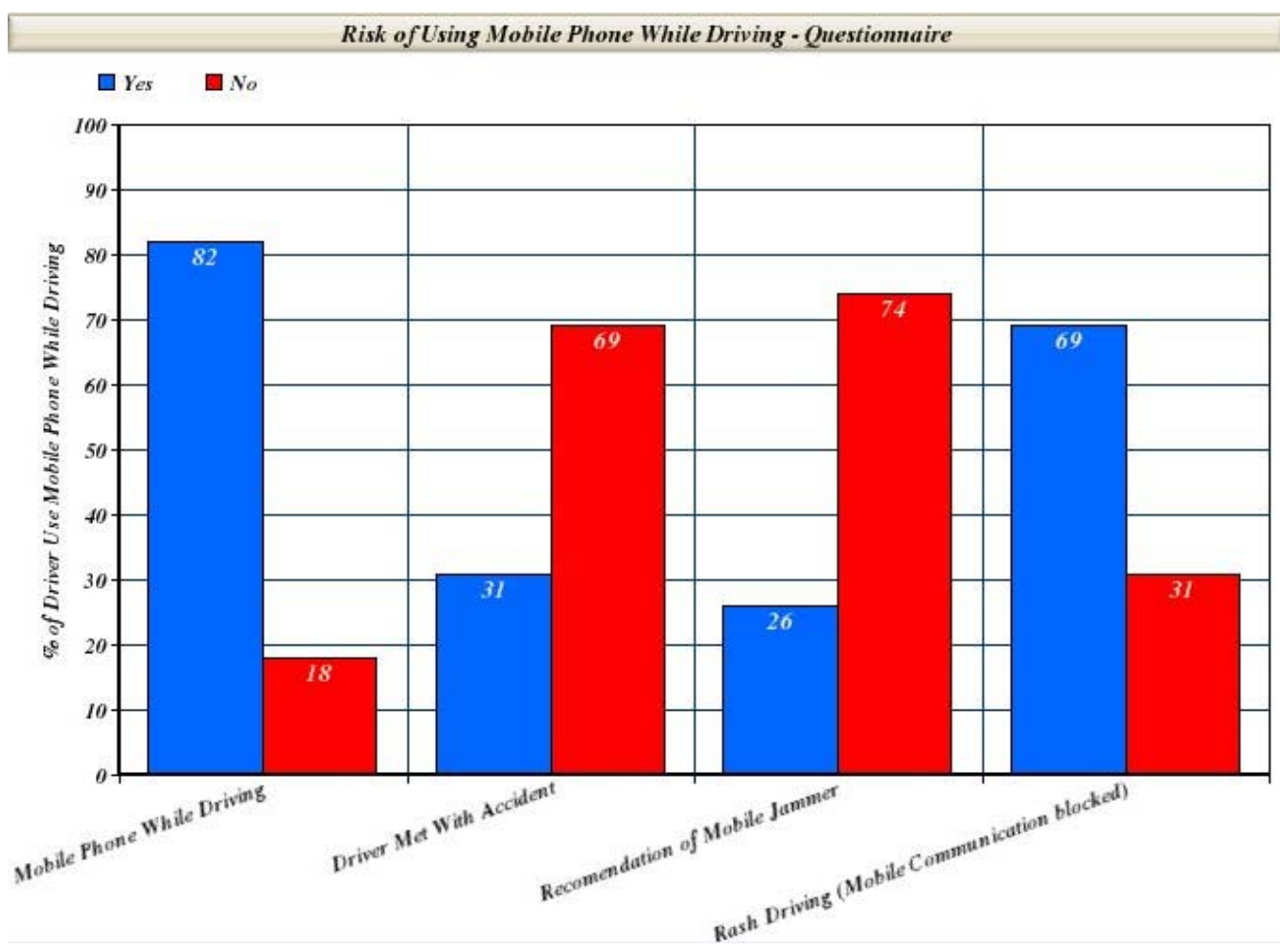

Figure 2. Questionnaires - Results 
From the above study it is apparent that though driver are knowledgeable with regards to the risks associated with usage of mobile phone while driving, they still are unwilling to give up the habit, unless effective technology was developed which provides the option to attend emergency calls ensuring the safety of the driver.

\section{Methodology}

\subsection{Driver Vs Passenger Challenge}

An electronic circuit as shown on Figure 3(a) was designed for automatic detection of incoming and outgoing calls on the driver's phone. Though various commercial systems do exists for detecting mobile phone. The trouble is that, these commercial systems do not have the ability to distinguish between cell phone user was either a passenger or the driver. Even under extreme condition i.e., when all passengers use the cell phone except the driver the circuit was able to distinguish that it is not the driver who is using the mobile phone. This circuit will get triggered ON when the vehicle gets started.

The RF amplifier circuit can detect the incoming or outgoing calls and text messages even if the mobile phone is kept in silent mode. Here the circuit uses a $0.22 \mu \mathrm{F}$ disk capacitor to capture the RF signals from the mobile phone. The disk capacitor along with the leads acts as a small gigahertz loop antenna to collect the RF signals from the mobile phone.

The combinations of both antenna and rectifier produce a direct current. Op-amp IC CA3130 is used in the circuit as a current-to-voltage converter, with the capacitor connected between its inverting and non-inverting inputs. The rectified DC voltage is amplified using voltage amplifier IC LM324 and it is stored in a large capacitor and then is digitised by an analogue-digital converter (ADC) for subsequent storage \& processing using a microcontroller.

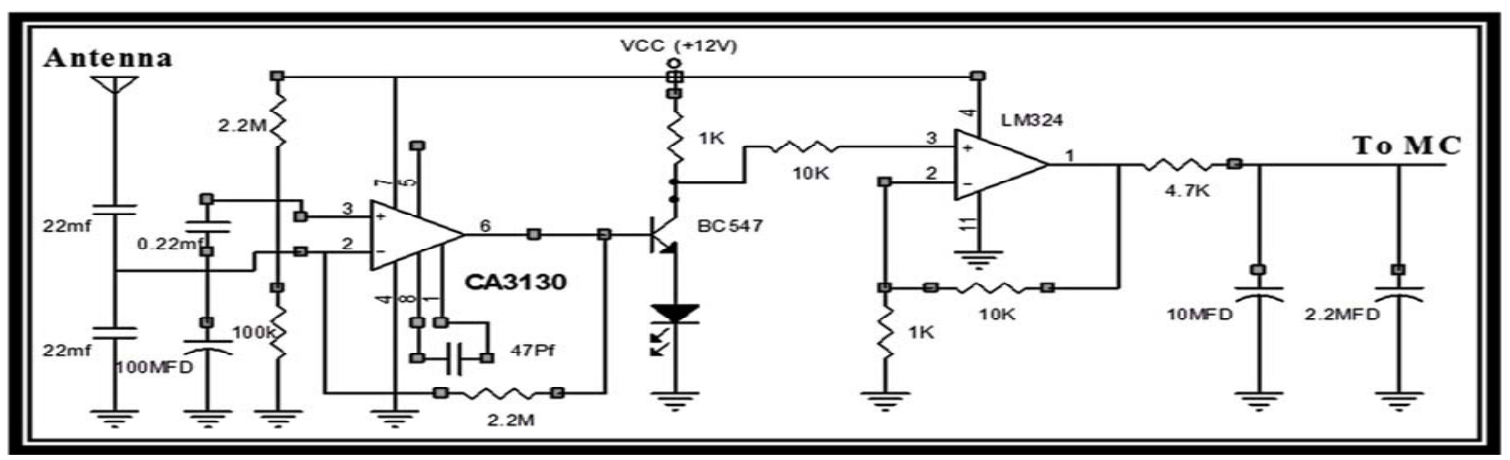

Figure 3(a). Mobile Phone Detection circuit

The voltage obtained with this system depends, on a number of factors including signal strength, the distance of the phone from the antenna and the relative orientation between the antenna and phone. This part of the circuit should be placed inside the vehicle on the top of the driver's seat to receive the RF radiation emitted by the mobile phone. This set-up facilitates more trustworthy discrimination of driver use of mobile phone than other developed systems. Figure 3(b) shows the snapshot of complete hardware arrangement and internal vehicle arrangement.

The output of RF amplifier stage is given to PIC16F917 microcontroller which executes the driver vs. passenger analysis algorithm. The microcontroller is programmed in such a way that, once the voltage level obtained from the RF amplifier stage is greater than the value of the voltage stored in EPROM of microcontroller, it identifies that the driver was using the cell phone and not the passenger. It will trigger a relay unit which will turn OFF, then immediately ON the cell phone. During start-up, the cell phone will automatically load a safety application named Cellphone Accident Preventer (C.A.P.) which is developed using a J2ME on the driver's cell phone which will eliminate the risk of accident. Furthermore the algorithm's output is transmitted to a laptop for recording purpose. Following this further analysis using MAX232, which is an integrated circuit that converts signals from an RS-232 serial port to signals suitable for use in TTL compatible digital logic circuits, can be carried out. 

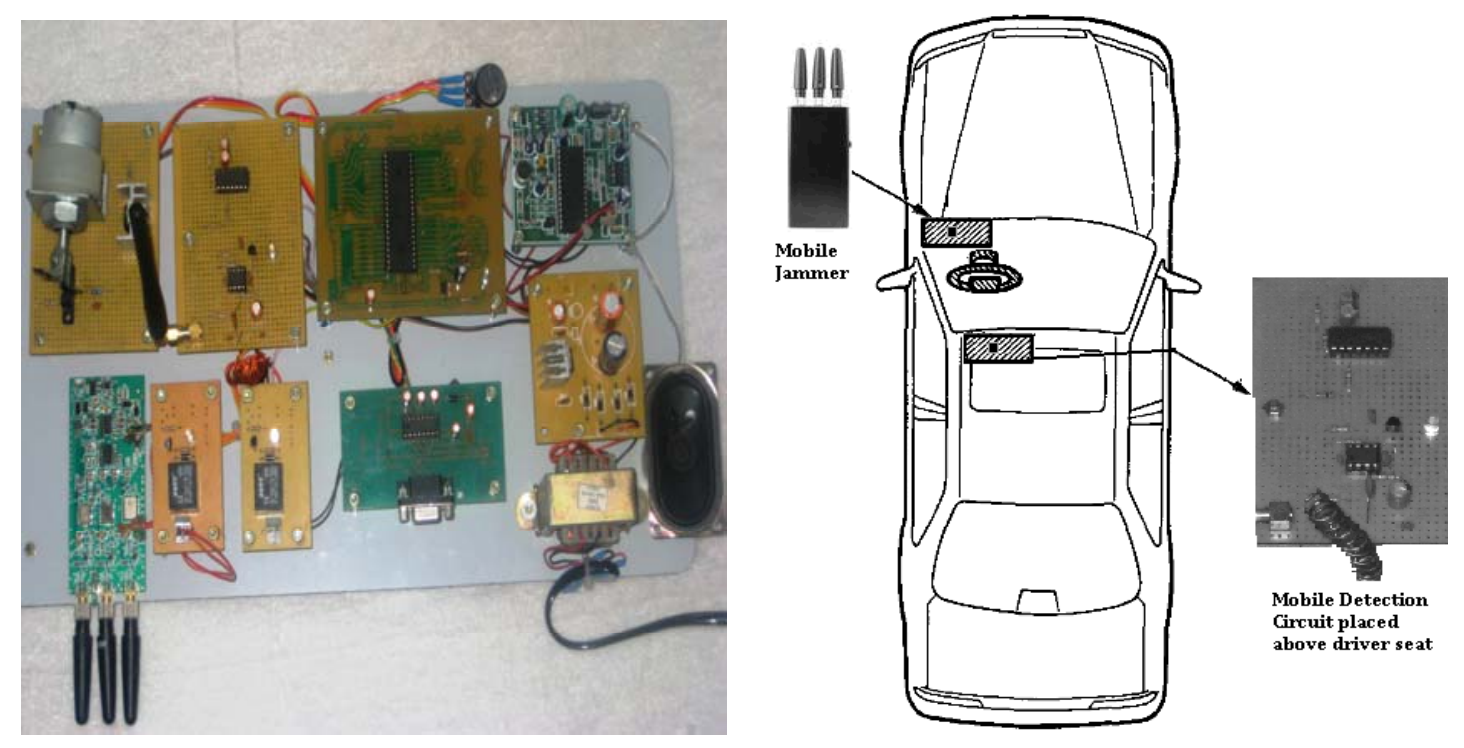

Figure 3(b). Hardware Implementation and internal vehicle arrangement

In this experiment, a call was made to the rear seat passenger and to the driver when the vehicle was moving. The call was maintained for a few seconds. An antenna which is placed above the driver's seat captures more energy from a mobile when compared to a rear seat passenger as shown on Figure 4(a) \& 4(c). Figure 4(b) shows the voice communication made by the driver. When the mobile phone is not in use, the energy captured is minimal and ranges from $3 \mathrm{mv}-5 \mathrm{mv}$. When a call is made from the driver seat, voltage obtained by the antenna will be high since the distance between cell phone and antenna is small. In other cases i.e., when call is made from the passenger seat, voltage captured will be low, since the distance between antenna and their cell phone will be far. Here, we have set the a threshold value at $200 \mathrm{mv}$, once the signal received by the antenna exceeds a threshold value it indicates whether the cell phone used was either the driver or passenger.
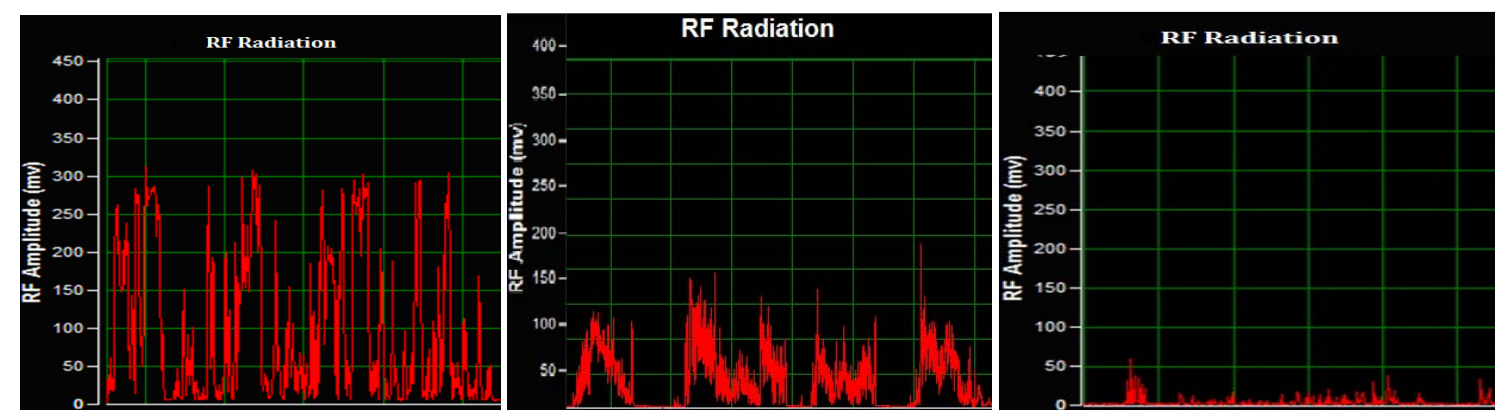

Figure 4. (a) \& (b) shows the drivers mobile phone power emission during phone ring and voice communication and (c) shows rear seat passenger power emission during ring and communication

\subsection{Mobile Application: Cellphone Accident Preventer (C.A.P.)}

C.A.P. is a mobile application designed to prevent road accidents which occur due to mobile phone use while driving. It will automatically load on the driver's cell phone when microcontroller detects the use of cell phone by the driver. C.A.P. comprises of various stages including (1) Measuring the current speed of the vehicle in which the mobile phone is being used (2) Compare the current speed with predefined threshold speed (3) Capture the incoming call event even before the phone rings and block the call once the speed is beyond a threshold value. (4) Send the message to the caller once the call is disconnected (5) Before Step (3) it will check whether the call is Emergency. Emergency call is one wherein the

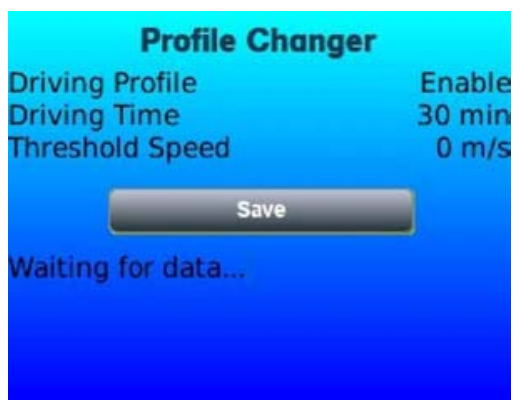

Figure 5. C.A.P. Setting Pane 
caller is calling from the same number thrice within the duration of 5 mins from the $1^{\text {st }}$ call. (6) In case of Emergency allow the call, and transfer the controller to microcontroller (7) Not allowing any outgoing call irrespective of threshold speed. The following figure 5 shows the C.A.P. application setting panel which contain:

- Driving profile: This is set to enable by default

- Driving time: This is the maximum time taken to reach the destination this can be set by the driver and

- Threshold speed: This is set to $2 \mathrm{~m} / \mathrm{s}$ by default above which C.A.P. application will start functioning.

\subsection{Measuring Current Speed}

Technology that is used today to measure the speed of the vehicle in motion uses Global positing system (GPS), signal strength, handover, speedometer or by using network based cellid. We have used a combination of network based cellid technique and GPS technology to measure the speed of the vehicle. Our application C.A.P. usually tries to obtain speed information from cellid technique because it is faster and consumes less power in indoor conditions when compared to GPS. We use GPS technology only when C.A.P fails to obtain speed information using cellid technique beyond $90 \mathrm{sec}$ and will switch back to cellid technique once we are able to get speed information as shown on Figure 6.
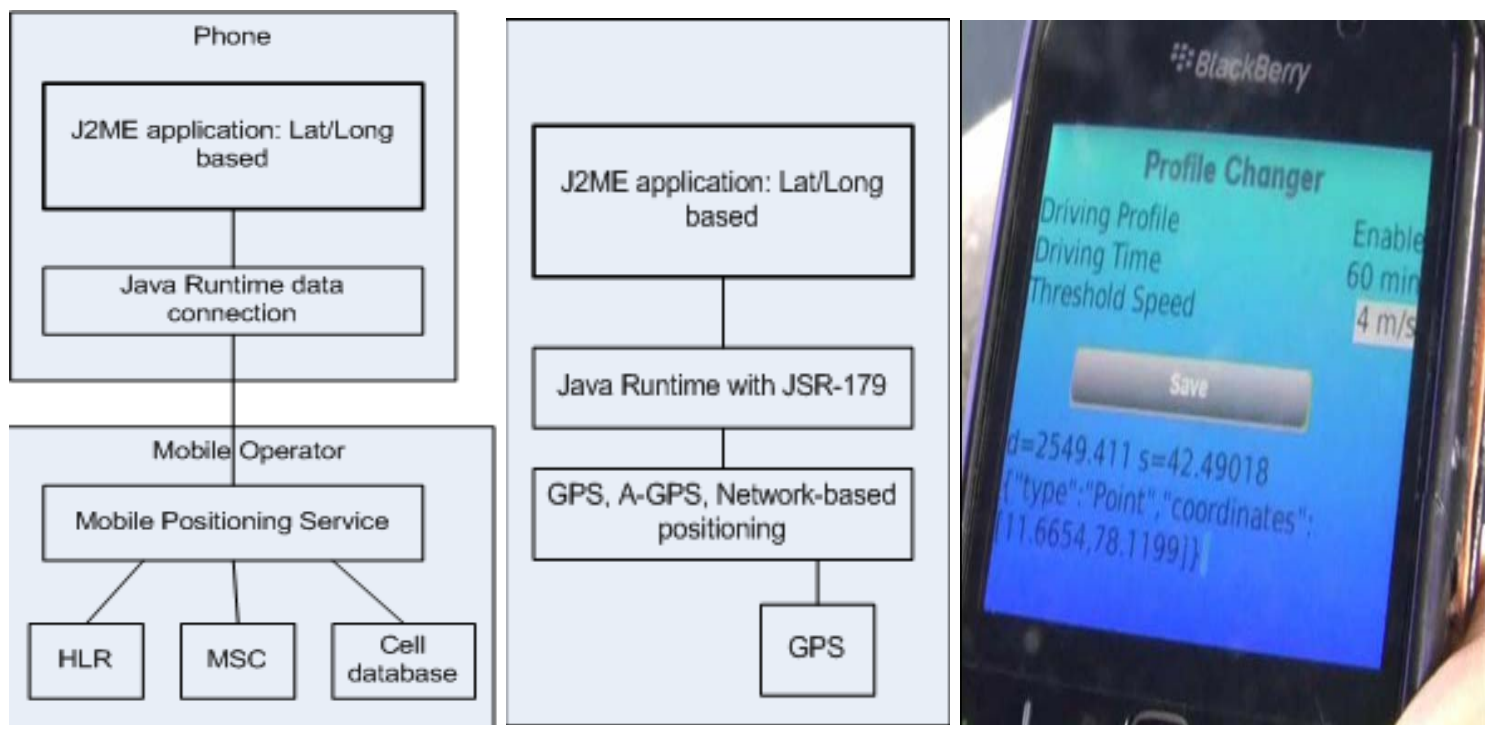

Figure 6. Measuring Speed Technique using Cellid and GPS

To obtain speed in a network based cellid technique, we have used class that provided on J2ME RIM package GPRSInfo. GPRSCellInfo to obtain Mobile country code (Mcc), Mobile network code (Mnc), Location area code (Lac) and Current cell id (Cellid). Using all of this information we create a query and send it to the database which contains a list of latitude and longitude coordinates corresponding to the cellid. In regular intervals there will be a change in these coordinates while driving providing information on distance travelled and speed which can be calculated using coordinate API method. The use of GPS technology helps input GPSInfo class to obtain latitude, longitude, altitude and speed.

\subsection{Handling Incoming Call Operation}

When a caller initiates a call, request will be forwarded to BTS. This request will then be sent to BSC to which it is connected. From BSC request it is then transferred to the MSC. Consequently MSC will made a request to HLR in order to check whether the caller has sufficient balance to make a call, area of the caller etc., MSC will establish a link between the two parties once the HLR sends back acknowledgement to the MSC. However, before the called MS get connected, Cellphone Accident Provider (C.A.P.) mobile application will check whether current speed of the vehicle is greater than threshold speed and also checks whether the call is an emergency call or not. If it is not an emergency call then application will disconnect the call and SMS will be sent to the caller through Short Message Service Center (SMSC) as shown on Figure 7. 


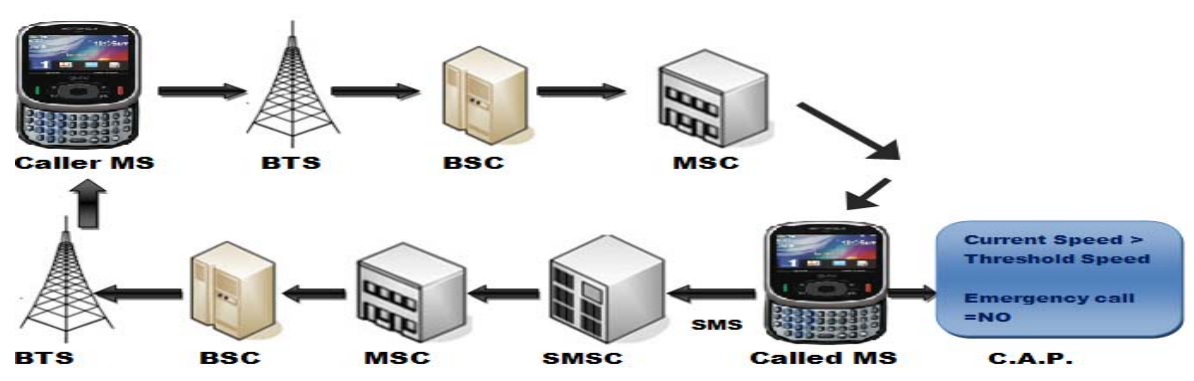

Figure 7. Handling Incoming Call

The message sent is based on various conditions:

$>$ If the caller calls for the $1^{\text {st }}$ time then he receives the message: "User is driving... please call back after XX minutes, and if an emergency, call back two more time continuously."

$>$ If the caller calls for the $2^{\text {nd }}$ time within 5 minutes from the 1 st call made, then he will receives the message: "User is driving... please call back after XX minutes, and if an emergency, call back one more time". As shown on Figure 8.

$>$ In case if the time interval between 2 calls is more than 5 minutes than application will consider it as first call.

Here, $\mathrm{XX}$ is the difference between the total time of the journey (set in the setting panel) and the time of the incoming call.

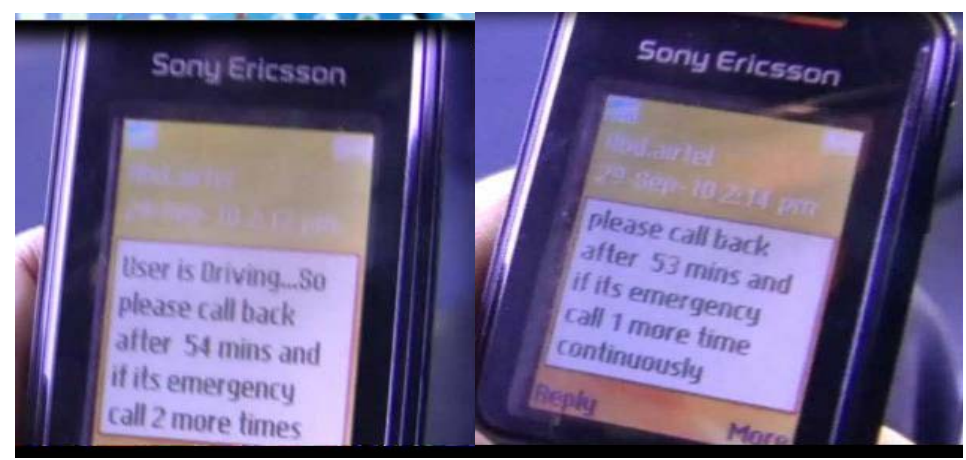

Figure 8 . SMS received by the caller on $1^{\text {st }}$ and $2^{\text {nd }}$ attempt respectively

If the caller calls for the $3^{\text {rd }}$ time within 5 min of duration from the $1^{\text {st }}$ call, then application consider this call as an emergency call and it allow the phone to start ringing as shown on Figure 9.

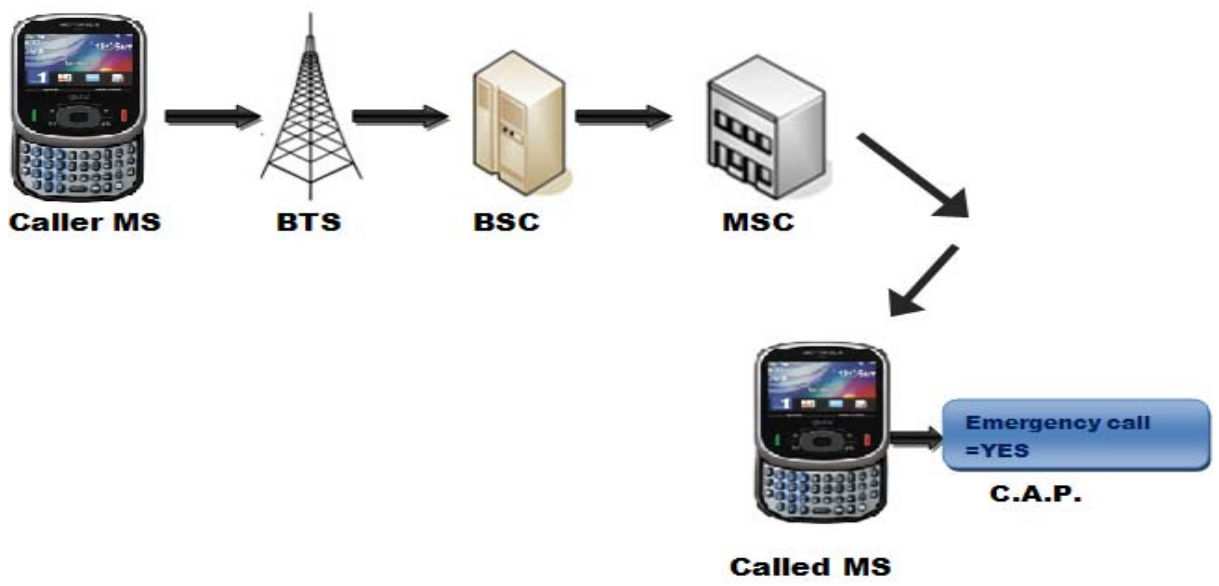

Figure 9. Handling Incoming Call during Emergency Call 
As discussed earlier, once the phone starts ringing, the mobile detection circuit will start capturing the radiation emitted by the phone. This time the microcontroller activates the voice chip which warns the driver through the speaker that "you have an emergency call. Please stop the vehicle in a safe place". Once microcontroller detects both the vehicle in motion along with voice communication and it will activate a mobile jammer. For the complete operation to take place, i.e., from the detection of mobile phone to the activation of mobile jammer takes approximately 25 seconds. Even during this time period, the driver may get easily distracted. In order to avoid the driver from talking on the phone during this timeframe a PIC16F877A microcontroller along with a KST-TX01 transmitter used to transmit the vehicle number plate information to the receiver KST-RX806 which is placed on the signal post. A PIC16F877A is programmed to transmit its ADC data (RA0/AN0 channel) serially using its built-in USART hardware at 1200 baud with no parity. The PIC's USART transmitter (TX) pin feeds the data into the data pin of the KST-TX01 which transmits it using $433 \mathrm{MHz}$ ASK RF signal as shown on Figure 10. On the receiving end the KST-RX806 module receives the data and its output is connected to another PIC's USART input pin. The second PIC is programmed to read its USART receiver (RX) pin and the obtained data will be displayed on LCD attached on the signal post so that the traffic police may take legislative action against the driver.

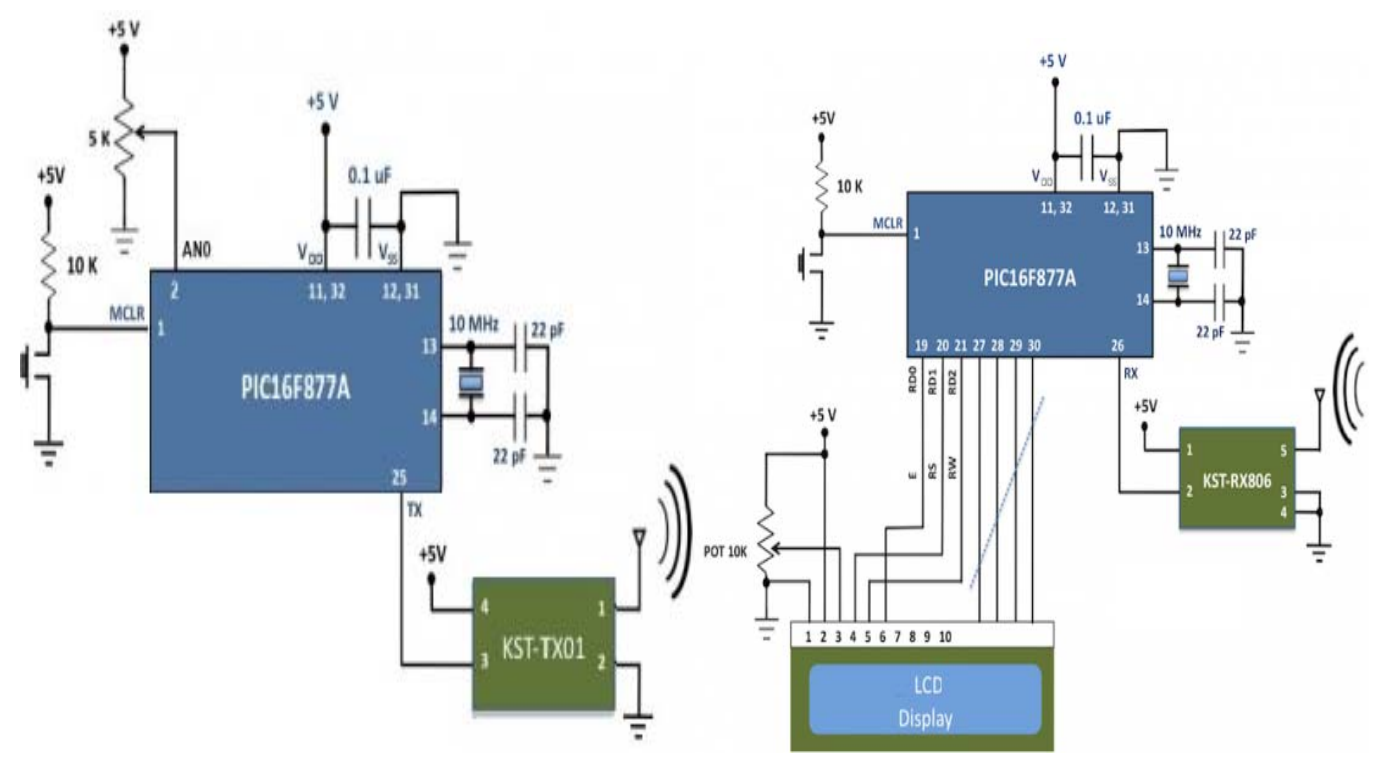

Figure 10. Automatic Transmission of Vehicle plate information to LCD

\subsection{Handling the Outgoing Call Event}

To get an outgoing call event we need to implement Phone Listener API which identifies all acts on the phone including events like call initiated, incoming call, call disconnection etc. Applications will block the user from making an outgoing call unless the driver stops and turn off the vehicle in a safe place as shown in the following figure 11.

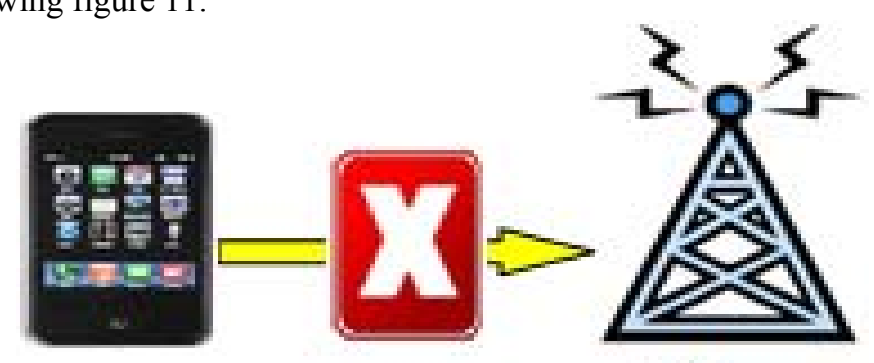

BTS

Figure 11. Handling Outgoing call 


\section{Experimental Evaluation}

To measure the efficiency of the system we install C.A.P. application to nearly 164 users out of which 18 users got an emergency call. Some of the users got the call during driving for the 1st time, and C.A.P. started sending the SMS to the caller with approx. elapsed time of the user to reach the destination. These callers made a call only after this elapsed time and by that time the user would have reached his destination safely. As a result, out of 164 people only 18 users were affected with the probability of risk associated with the driving after installing this application, showing a risk rate of only $10.3 \%$ during incoming call. In case of an outgoing call the risk associated with the driver after installing this application is $0 \%$ since C.A.P. application blocks all outgoing call until the user comes to rest or stops the vehicle in a safe place. Figure 12 below shows how far the C.A.P. application is effective when compared with other top Cellphone distracted application.

\begin{tabular}{|c|c|c|c|c|c|c|c|}
\hline Name & $\begin{array}{l}\text { Application } \\
\text { (App)/ } \\
\text { Hardware } \\
\text { (HW) }\end{array}$ & $\begin{array}{l}\text { Driver } \\
\text { Detection }\end{array}$ & $\begin{array}{l}\text { Human } \\
\text { Intervention }\end{array}$ & Trigger & $\begin{array}{l}\text { Notification } \\
\text { to caller }\end{array}$ & $\begin{array}{l}\text { Technology } \\
\text { Required }\end{array}$ & $\begin{array}{l}\text { Subscription } \\
\text { /Price }\end{array}$ \\
\hline CellControl & App/HW & No & Required & Speed & No & Bluetooth & $\begin{array}{l}\text { Yes } / \$ 25+\$ 8 \\
\text { per month }\end{array}$ \\
\hline iZUP & App & No & Required & Speed & No & GPS & $\begin{array}{l}\text { Yes } / \$ 20 \text { per } \\
\text { year }\end{array}$ \\
\hline DriveAssist & App & No & Required & Speed & Yes & GPS & Yes \\
\hline $\begin{array}{l}\text { Key2Safe } \\
\text { diving }\end{array}$ & App/HW & No & Required & Ignition & No & Bluetooth & No/\$99.95 \\
\hline $\begin{array}{l}\text { Drive Smart } \\
\text { Plus }\end{array}$ & App & No & Required & Speed & No & GPS & $\begin{array}{l}\$ 4.99 \text { per } \\
\text { month }\end{array}$ \\
\hline CellTRAKR & App & No & Required & Speed & Yes & GPS & Free \\
\hline PhonEnforcer & App & No & Required & Speed & $\begin{array}{l}\text { Notify to } \\
\text { predefined } \\
\text { number. Not } \\
\text { to the caller. }\end{array}$ & GPS & $\begin{array}{l}\text { Yes/Price } \\
\text { depends on } \\
\text { various } \\
\text { versions. }\end{array}$ \\
\hline $\begin{array}{l}\text { C.A.P } \\
\text { (Cellphone } \\
\text { Accident } \\
\text { Preventer) }\end{array}$ & HW/App & Yes & $\begin{array}{l}\text { NOT } \\
\text { Required }\end{array}$ & $\begin{array}{l}\text { Voice or Data } \\
\text { communicati- } \\
\text {-on }\end{array}$ & Yes & $\begin{array}{l}\text { GPS if } \\
\text { Required. }\end{array}$ & Free \\
\hline
\end{tabular}

Figure 12. C.A.P vs. Other Cellphone distraction application

\section{Indian Economic Impact on Accidents}

As per data registered by the World Health organization, nearly 13-14 million people are known to die each year due to road accidents globally. Out of this figure nearly 1.35 lakhs people are killed in India. This shows that 369 people die every day on Indian roads. According to statistics obtained from India Ministry of Road Transport \& Highways at least 15 people die every hour in road accidents in 2010 when compared to 14 in 2009 refer Figure 13(a).

\begin{tabular}{|c|c|c|c|c|}
\hline Road Accidents & \multicolumn{2}{|c|}{ Daily Statistics } & \multicolumn{2}{c|}{ Hourly Statistics } \\
\hline Statistics & World & India & World & India \\
\hline Death (2010) & 3837 & 369 & 160 & 15 \\
\hline Death (2009) & 3561 & 344 & 148 & 14 \\
\hline
\end{tabular}

\begin{tabular}{|c|c|c|c|c|}
\hline Road Accidents & \multicolumn{2}{|c|}{ Daily Statistics } & \multicolumn{2}{c|}{ Hourly Statistics } \\
\hline Statistics & World & India & World & India \\
\hline Death (2010) & 3837 & $\mathbf{3 6 9}$ & 160 & $\mathbf{1 5}$ \\
\hline $\begin{array}{c}\text { Injuries (2010) } \\
\begin{array}{c}\text { Death + Injuries } \\
\text { (2010) }\end{array}\end{array}$ & 109,589 & $\mathbf{1 3 6 9}$ & 4566 & $\mathbf{5 7}$ \\
\hline
\end{tabular}

Figure 13. (a) Road Accidents Comparison on 2010 vs. 2009 and (b) Total number of Accidents in 2010 
Due to coordinate inter agency approaches in developed countries, the situation is improving. However, projections indicate that unless there is a new strong political commitment to prevention, the crash death rate in low and middle-income countries will double by 2020, reaching more than 2 million people per year. Road crash injuries impose substantial economic burdens on developing nations like India estimating 3 percent of gross national product. The estimated cost includes compensation, asset loss, time and energy spent on police, hospital, court cases and work loss cost value productivity loss. They also include victims lost wages and the replacement cost of lost household work.

According to our study estimates that $31 \%$ of crashes are caused by a driver using his or her cell phone with financial losses of 3\% GDP every year. Therefore in India it can be estimated that the total loss due to road accidents was ' 108 crores per day. According to our study estimation, total number crashes due to mobile phone usage while driving every day can be calculated as, $31 \%$ of $1738=539$.

Therefore, 539 crash per day due to mobile phone usage. In India the total cost spent is approximately ' 108 Crores per day for 1738 crashes which includes deaths and injuries as shown on Figure 13(b). Hence '33.5 Crores spent is for crashes involved in mobile phone usage. As discussed earlier, if we install C.A.P application in mobile phones while driving the chances of involvement in crashes is $10.3 \%$ So, $10 \%$ of $539=53.9$ (Approx. 54). Hence we can save nearly 500 crashes which in turn reduce the economic loss of India to 78 crores from $108 \mathrm{cr}$ and with improving personal family benefits. We further carried out the step in reducing $10.3 \%$ of mobile phone crashes by implementing automatic transmission of vehicle number plate information to the police. Hence implementation of the above proposed system along with C.A.P application will reduce more than a quarter of crashes and economic losses of India.

\section{Conclusions}

To prevent the occurrence of accident due to mobile phone use by drivers an attempt has been made to provide a low-cost, non-invasive; small-size system which is capable of differentiating the use of cell phone is either by the driver or the passengers. The small-size hardware system and the Cellphone Accident Preventer (C.A.P.) mobile application along with low range mobile jammer is used to detect the driver's use of mobile phone, while ignoring the phone used by the fellow passenger in the vehicle and possessing the ability to block the mobile communication only in the driver seating area while providing an option for the driver to attend an emergency call if he stops a vehicle at a safe. The PIC16F877A microcontroller along with a KST-TX01 transmitter is used to transmit the vehicle number plate information to the receiver KST-RX806 placed on the signal post. The received data will be displayed on LCD (owned by police) once the driver starts using the phone without stopping the vehicle, and before the activation of mobile jammer unit is detected, so that, traffic police can take legislative action against the driver. Therefore, the implementation of this proposed system would prevent the road accident by reducing the drivers' distraction to a large extent.

\section{References}

1. Healey, J. A., Picard, R. W. (2005). Detecting stress during real-world driving tasks using physiological sensors. IEEE Transactions on Intelligent Transportation Systems, 6(2), 156-166.

2. McCartt, A. T., Hellinga, L. A., Bratiman, K. A. (2006). Cell Phones and Driving: Review of Research. Traffic Injury Prevention, 7, 89-106.

3. McEvoy, Suzanne P., Stevenson, Mark R., McCartt, Anne T. et al. (2005). Role of Mobile Phones in Motor Vehicle Crashes Resulting in Hospital Attendance: A Case-Crossover Study. British Medical Journal, 331(7514), 428-430.

4. Walsha, Shari P., Whitea, Katherine M., Hydea Melissa K., Watsonb, Barry. (2008). Dialling and driving: factors influencing intentions to use a mobile phone while driving. Accident Analysis \& Prevention, 40(6), 1893-1900.

5. Lee, John D., McGehee, Daniel V., Brown, Timothy L., Reyes, Michelle L. (2002). Collision warning timing, driver distraction, and driver response to imminent rear-end collisions in a high-fidelity driving simulator. Human Factors, 44(2), 314-334.

6. Shabeer, H. A., Wahidabanu, R. S. D. (2009). Automatic Switching of Mobile Phone Profile Based on Current Speed of the Vehicle and Mobile Phone Security. CiiT International Journal of Wireless Communication, August 2009, 78-86.

7. Redelmeier, D. A., Tibshirani, R. J. Association between cellular-telephone calls and motor vehicle collisions. New England Journal of Medicine, 336, 453-458.

8. Jie Yang, Simon Sidhom, Gayathri Chandrasekaran, Tam Vu, Hongbo Liu, Nicolae Cecan, Yingying Chen, Gruteser, Marco, Martin, Richard P. (2011). Detecting driver phone use leveraging car speakers. 
In Proceedings of the International Conference on Mobile Computing and Networking, September 19-23 (pp. 97-108). Las Vegas, Nevada, USA.

9. Hon Lung Chu, Vijay Raman, Jeffrey Shen, Romit Roy Choudhury, Aman Kansal and Bahl, Victor. (2011). In-Vehicle Driver Detection Using Mobile Phone Sensors. In Proceedings of the International Conference on Mobile Systems, Applications and Services, June $28^{\text {th }}-$ July $1^{\text {st }}$. Washington, USA.

10. Amardeep Sathyanarayana, Sandhya Nageswaren and Hassan Ghasemzadeh. (2008). Body sensor networks for driver distraction identification. In Proceedings of the IEEE International Conference on Vehicular Electronics and Safety, September 22-24 (pp. 120-125). Columbus Ohio, USA: IEEE.

11. McCall, J. C., Mallick, S. P., Trivedi, M. M. (2003). Real-time Driver Affect Analysis and Televiewing System. In Proceedings of the IEEE Intelligent Vehicles Symposium, June 9-11 (pp. 372-377). Columbus Ohio, USA: IEEE.

12. Huang, K, Trivedi, M. M. (2003). Driver Head Pose and View Estimation with Single Omnidirectional Video Stream. In Proceedings of the $3^{\text {rd }}$ International Conference on Computer Vision Systems, April 3 (pp. 44-51). Graz, Austria: IEEE.

13. Sharon, T., Selker, T, Wagner, L., Frank, A. J. (2005). Car Coach: A Generalized Layered Architecture for Educational Car Systems. In Proceedings of the IEEE International Conference on Software-Science, Technology, Engineering, February 22-23 (pp. 13-22). Herzelia, Israel: IEEE.

14. McCall, J. C., Achler, O., Trivedi, M. M. (2004). Design of an Instrumented Vehicle Test Bed for Developing a Human Centered Driver Support System. In Proceedings of the IEEE Intelligent Vehicles Symposium, June 14-17 (pp. 483-488). Parma, Italy: IEEE.

15. Harbluk, J. L., Noy, Y. I., Eizeman, M. (2002). The impact of cognitive distraction on driver visual behaviour and vehicle control. Canada: Road Safety Directorate and Motor Vehicle Regulation.

16. Strayer, D. L., Drews, F. A. and Johnston, W. A. (2003). Cell phone-induced failures of visual attention during simulated driving. Journal of Experimental Psychology: Applied, 9(1), 23-32.

17. Crundall, D., Bains, M., Chapman, P. and Underwood, G. (2005). Regulating conversation during driving: A problem for mobile telephone? Transport Research Part F, 8(3), 197-211.

18. James, N. (2011). Don't Be Distracted about Distracted Driving. Quarterly Review of Advanced Risk Management Strategies, 25(3), 24-31.

19. Azman, A., Meng, Q. and Edirisinghe, E. (2010). Correlation between eye movements and mouth movements to detect driver cognitive distraction. In Proceedings of the International Conference: Brain Inspired Cognitive Systems (BICS), $16^{\text {th }}$ July 2010. Madrid, Spain.

20. Rongben, W., Lie, G., Bingliang, T. and Lisheng, J. (2004). Monitoring mouth movement for driver fatigue or distraction with one camera. In IEEE Intelligent Transportation Systems, October 3-6, (pp. 314-319). Washington, D. C, USA: IEEE.

21. Hayhoe, M. M. (2004). Advances in relating eye movements and cognition. Infancy, 6(2), 267-274.

22. Liang, Y., Lee, J. D. and Reyes, M. L. (2007). Non-intrusive detection of driver cognitive distraction in real-time using Bayesian networks. Journal of the Transportation Research Board, 2018, 1-8.

23. Fisher, L. D., Knodler, M. and Muttart, J. (2009). Driver-Eye-Movement-Based Investigation for Improving Work-Zone Safety. England: The New England Transportation Consortium.

24. Pohl, J., Birk, W. and Westervall, L. (2007). A driver-distraction-based lane-keeping assistance system": Proceedings of the Institution of Mechanical Engineers, Part I. Journal of Systems and Control Engineering, 221(14), 541-552.

25. Takemura, K., Ido, J., Matsumoto, Y. and Ogasawara, T. (2003). Development of Non-contact drive monitoring system for advanced safety vehicle: IEEE/ASME Proceedings of the International Conference 'Advanced Intelligent Mechatronics', July 20-24 (pp. 1119-1122). Kobe, Japan: IEEE

26. Wesley, A., Shastri, D. and Pavlidis, I. (2010). A Novel method to monitor driver's distractions. In Proceedings of the International Conference: Human Factors in Computing Systems (CHI), April 10-15 (pp. 4273-4278). Atlanta, Georgia: ACM.

27. Smith, P., Shah, M. and Vitoria, N. L. (2003). Determining driver visual attention with one camera. IEEE Transaction Intelligent Transportation Systems, 4(4), 2058-2218.

28. Jannette, M. and Mark, V. (2009). Comparison of manual vs. speech-based interaction with in-vehicle information systems. Accident Analysis and Prevention, 41(5), 924-930.

29. Gellatly, A. and Dingus, T. (1998). Speech Recognition and Automotive Applications: Using Speech to Perform In-Vehicle Tasks. In Proceedings of the International Conference: Human Factors '98, October 5-9 (pp. 1247-1251). Santa Monica, CA: Human Factors and Ergonomics.

30. Liang, Y., Lee, J. D. and Reyes, M. L. (2007). Non-intrusive detection of driver cognitive distraction in real-time using Bayesian networks. Journal of the Transportation Research Board, 2018, 1-8.

31. Liang, Y., Reyes, M. L. and Lee, J. D. (2007a). Real-time detection of driver cognitive distraction using Support Vector Machines. IEEE Intelligent Transportation Systems, 8(2), 340-350. 
32. Zhang, Y., Owechko, Y. and Zhang, J. (2007). Driver cognitive workload estimation: a data-driven perspective: IEEE Proceedings of the International Conference. In Intelligent Transportation Systems (pp. 642-647). Washington, D. C., USA: IEEE.

33. Green, P. (1999). Visual and Task Demands of Driver Information Systems. Ann Arbor, Michigan, USA: University of Michigan, Transportation Research Institute.

34. Abdul Shabeer, H. and Wahida Banu, R. S. D (2011). A Novel Approach to Avoid Mobile Phone Accidents While Driving and Cost- Effective Fatalities. International Journal of Interdisciplinary Telecommunication and Networking, 3(3), 29-39.

35. Janne, L. and Jason, H. (2011). Undistracted Driving: A Mobile Phone that Doesn't Distract. In Proceedings of the $12^{\text {th }}$ Workshop on Mobile Computing Systems and Applications, March 1-2 (pp. 146-154). Phoenix, Arizona, USA: ACM.

36. Stewart, Marie. (2010). Sensing motion in a mobile phone and limiting functionality of moving phones. USA: USA Distracted Driving Foundation.

37. Klauer, S. G., Dingus, T. A., Neale, V. L., Sudweeks, J. D. and Ramsey, D. J. (2006). The impact of driver inattention on near-crash risk: An analysis using the 100-car naturalistic driving study data. Washington, DC: National Highway Traffic Safety Administration.

38. Use of the mobile phone while driving. SWOV Fact Sheet. (2010). Leidschendam, the Netherlands.

39. National Center for Statistics and Analysis. (2009). Driver electronic device use in 2008. Traffic Safety Facts Research Note (DOT HS 811 184). Washington, DC: National Highway Traffic Safety Administration.

40. Scott, David A. Hands-free phones just as dangerous in Cars. Retrieved July 6, 2011, from

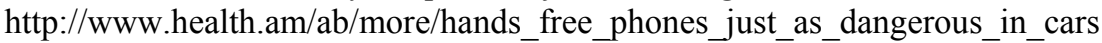

41. Ogg, Erica. Cell phones as dangerous as $\overrightarrow{d r u n k} \overline{d r i v i n g . ~ R e t r i e v e d ~ J u l y ~ 1, ~ 2006, ~ f r o m ~}$ http://news.cnet.com/8301-10784_3-6090342-7.html\#ixzz10HaYIDvx

42. Benton, Joe. Cell Phone No. 1 Driver Distraction Retrieved April 20, 2006, from http://www.consumeraffairs.com/news04/2006/04/cell_phones_distraction.html \#ixzz10Hc71p00

43. Times of India. Article. Road accidents cost India Rs 1 lakh crore a year. Retrieved October 4, 2011, from http://timesofindia.indiatimes.com/india/Road-accidents-cost-India-Rs-1-lakh-crore-ayear/articleshow/10224908.cms

44. Kent, Peter. Cell Phone and Automobile Accidents on the Rise. Retrieved April 18, 2008, from http://www.articlesbase.com/automotive-articles/cell-phone-and-automobile-accidents-on-the-rise390037.html\#ixzz10HgLel8M

45. Thaindian News. Article. Strong link between mobile use and road accidents found. Retrieved September 15, 2008, from http:/www.thaindian.com/newsportal/world-news/strong-link-betweenmobile-use-and-road-accidents-found_10096231.html\#ixzz10Hublokz

46. Deutsche Welle. India has the highest number of road accidents in the world. Retrieved April 30, 2010, from http://www.ethiopianreview.com/news/90301

47. Dipak Kumar Dash. India leads world in road deaths: WHO. Retrieved August 17, 2009, from http://timesofindia.indiatimes.com/india/India-leads-world-in-road-deaths-

WHO/articleshow/4900415.cms 